\title{
Sistem Informasi Geografis Pemetaan Sekolah Menengah Atas / Sederajat di Kota Surakarta Menggunakan Leaflet Javascript Library Berbasis Website
}

\author{
Ridwan Renaldi ${ }^{1}$, Dimas Aryo Anggoro ${ }^{2}$ \\ Program Studi Informatika \\ Universitas Muhammadiyah Surakarta \\ Surakarta, Indonesia \\ Email: ${ }^{1}$ renaldiridwan009@gmail.com, ${ }^{2}$ dimas.a.anggoro@ums.ac.id2
}

\begin{abstract}
Abstraksi-Pendidikan merupakan salah satu sektor terpenting yang perlu dikembangkan untuk meningkatkan kualitas sumber daya manusia. Banyaknya jumlah sekolah di kota Surakarta, memberikan kesempatan kepada calon peserta didik dan orang tua murid untuk dapat memilih sekolah yang sesuai keinginan. Akan tetapi cukup sulit untuk mendapatkan informasi mengenai profil sekolah serta lokasi keberadaanya yang tidak banyak orang tahu dan menjadikan hambatan bagi orang tua dalam menentukan pilihan sekolah untuk anaknya. Target dari penelitian ini adalah untuk mempersiapkan dan mengembangkan Sistem Informasi Geografis berbasis website untuk pesebaran SMA / SMK di kota Surakarta dengan menggunakan Library Leaflet Javascript untuk menampilkan peta persebaran SMA / SMK. Aplikasi ini mengizinkan pengguna untuk mencari lokasi sekolah di sekitar pengguna dan membagikan informasi tentang profil sekolah. Diharapkan aplikasi ini berdampak kepada masyarakat dalam memudahkan mencari informasi mengenai lokasi dan profil sekolah di Kota Surakarta. Pengembangan sistem menggunakan metode sekuensial linier (Waterfall) dan dibuat dengan beberapa komponen yaitu HTML, CSS, Javascript, PHP dan mysql. Perwujudan dari penelitian ini yaitu webgis yang bisa memperlihatkan lokasi persebaran sekolah dan profil sekolah di kota Surakarta. Berdasarkan hasil pengujian metode Black-box webgis yang dibuat dapat berjalan sesuai dengan fungsionalitasnya. Pada pengetesan metode SUS diperoleh score SUS yaitu 79,4, menunjukan sistem diterima oleh masyarakat. Kesimpulan yang di dapat pada penelitian ini adalah Library Leaflet mempermudah dalam pembuatan peta, sistem dapat menampilkan lokasi pada peta dan informasi profil sekolah serta sistem dapat berjalan dengan baik.
\end{abstract}

Kata Kunci-Geografis, Leaflet, Pemetaan , Webgis

\section{PENDAHULUAN}

Dalam kehidupan di Indonesia Pendidikan adalah salah satu faktor penting yang harus dikembangkan. Pendidikan merupakan sebuah jalan usaha sadar dan sistematis untuk menciptakan situasi belajar mengajar dan jalan pembelajaran supaya peserta didik dapat secara aktif mengembangkan dirinya agar memiliki kemampuan spiritual keagamaan, pengendalian diri, karakter, kecerdasan, akhlak mulia serta keahlian yang diperlukan dirinya, masyarakat, bangsa dan Negara (UU No.20 tahun 2003).

Pesatnya pertumbuhan sekolah di Kota Surakarta pada jenjang sekolah menengah atas (SMA) maupun sekolah menengah kejuruan (SMK) baik berstatus negeri maupun swasta memiliki kriteria tersendiri tiap jurusannya [1]. Banyaknya sekolah yang tersebar di kota Surakarta dan minat masyarakat yang ingin menempuh pendidikan di tingkat SMA atau SMK membuat mereka ingin mendapatkan informasi yang akurat sehingga harus mendatangi SMA atau SMK tersebut. Akan tetapi terdapat kendala seperti jauhnya lokasi sekolah yang ingin dituju terlebih lagi untuk orang yang berasal dari luar Kota Surakarta. Mereka harus bertanya pada orang yang berasal dari Kota Surakarta untuk mendapatkan informasi sekolah serta banyaknya waktu yang terbuang dalam mengumpulkan informasi sekolah yang sesuai dengan keinginan. Informasi yang disajikan oleh Dinas Pendididkan Kota Surakarta pada halaman websitenya hanya berupa peta kecamatan dengan informasi jumlah sekolah dari SD sampai SMA pada tiap kecamatannya. Masih kurang lengkapnya informasi yang disampaikan dapat menyulitkan masyarakat dalam mengetahui persebaran sekolah yang berada di kota Surakarta.

Dinas Pendidikan di kota Surakarta pada saat ini sudah menetapkan sistem zonasi pada penerimaan calon peserta didik baru mulai dari SD sampai SMA. Sistem zonasi sekolah ini sudah diatur dalam keputusan dinas pendidikan kota Surakarta tahun pelajaran 2018/2019 [2]. Dengan adanya peraturan pendidikan dengan sistem zonasi ini terdapat poin penting dalam penyelenggaraan bidang pendidikan. Sistem zonasi memaksa masyarakat (calon peserta didik baru) untuk mendaftar pada sekolah yang lokasinya dekat dari tempat tinggal. Bagi peserta didik baru yang lokasi rumahnya jauh dari lokasi sekolah favorit memiliki kesempatan lebih kecil untuk diterima di sekolah tersebut, karena yang diutamakan adalah yang terdekat [3]. Sehingga siswa yang berkompeten akan tersebar merata 
sesuai zonasi, tidak terkumpul pada satu sekolah saja. Dengan demikian tidak ada lagi sekolah favorit. Adanya sistem zonasi pada saat ini membuat masyarakat khususnya orang tua menjadi lebih sulit dalam memilih sekolah untuk anaknya. Oleh sebab itu peneliti membuat sistem informasi geografis yang dapat menjadi solusi dari masalah tersebut.

Sistem informasi geografis yang dalam bahasa inggris dapat disebut Geographic Information System (GIS) adalah sistem informasi yang memiliki keunikan yaitu mengelola dan memproses data spasial (keruangan), atau dalam artian lain yaitu sistem yang memiliki struktur yang dapat untuk membuat, menyimpan, mengelola serta dapat menyajikan informasi dalam bentuk peta geografis, seperti data koordinat lokasi suatu tempat, yang dapat disimpan pada database [4]. Aplikasi GIS pada saat ini banyak digunakan atau dipublikasikan melalui internet. Salah satunya yaitu web-based GIS atau lebih dikenal dengan sebutan WebGIS. Karena berbasis website maka aplikasi ini membutuhkan browser dan internet untuk menjalankannya. WebGIS dapat dibuat berdasarkan kebutuhan sesuai bidang yang diinginkan, salah satunya adalah pembuatan WebGIS dalam bidang pendidikan yang dapat digunakan sebagai pemetaan sekolah yang tersebar di suatu wilayah khususnya di kota Surakarta [5]. WebGIS nantinya dapat digunakan sebagai panduan masyarakat khsusnya orang tua dalam mencari lokasi persebaran serta informasi mengenai sekolah yang ada di kota Surakarta.

Penelitian tentang GIS ini sudah banyak dilakukan oleh peneliti lain diantaranya yaitu Sistem Informasi Pemetaan Sekolah Berbasis Mobile [6]. Dalam penelitiannya menghasilkan aplikasi GIS untuk menolong masyarakat dalam menemukan lokasi dan informasi profil sekolah yang ada di kecamatan Tampan Pekanbaru, yang dijalankan pada perangkat Android. Serta penelitian tentang Sistem Informasi Pemetaan Sekolah Berbasis Web [7]. Dalam penelitiannya dihasilkan WebGIS yang memudahkan masyarakat khususnya di kecamatan wonodadi kabupaten Blitar dalam memberikan informasi mengenai lokasi sekolah yang dapat di akses dimana saja menggunakan internet. Dari beberapa penelitian tersebut dapat disimpulkan bahwa GIS dapat dibuat untuk memudahkan masyarakat dalam memperoleh informasi sekolah. Akan tetapi sistem yang dibuat masih menggunakan Google Maps API dalam membuat peta pemetaan sekolah. Dimana diperlukan token untuk melakukan permintaan ke Google Maps API yang dimana memiliki batasan permintaan. Dalam penelitian ini peneliti akan menggunakan leaflet untuk membuat peta pada website. Leaflet adalah library javascript yang dibangun untuk membantu pembuatan peta interaktif pada website yang bersifat open source [8]. Jika dibandingkan dengan Google Maps API, Leaflet menyediakan banyak plugin untuk memperluas fungsionalitas seperti menambahkan pin pada peta, pop up atau bahkan fitur untuk menggunakan gps [9].

Peneliti mengambil penelitian ini dengan tujuan untuk merancang serta membangun Sistem Informasi Geografis berbasis website yang disebut WebGIS. Teknologi GIS mengalokasikan sumber-sumber dari database untuk memvisualisasikan gambargambar pada peta [10]. Sistem yang dibuat dalam penelitian ini menggunakan Leaflet Library Javascript yang akan ditampilkan melalui website agar mempermudah dalam penyampaian infor- masi tentang pesebaran sekolah di kota Surakarta. Sehingga masyarakat (orang tua) tidak lagi terkendala dalam memperoleh informasi sekolah yang ada di kota Surakarta.

\section{METODE PENELITIAN}

Dalam mengembangkan Sistem Informasi Geografis Pemetaan Sekolah Menengah Atas / Sederajat Di Kota Surakarta Menggunakan Leaflet Javascript Library Berbasis Website metode yang digunakan penulis adalah metode Waterfall. Metode tersebut dipakai dalam pendekatan untuk peningkatan software yang digunakan dalam merancang proyek dengan siklus hidup yang sekuensial linier [11]. Model SDLC diantaranya adalah model waterfall, model ini sudah digunakan sejak lama dan menjadi model yang tertua serta dikenal banyak kalangan. Dalam model ini memiliki beberapa tahap yang harus dilalui, dimulai dari analisis kebutuhan, desain, pengkodean, pengujian serta pemeliharaan yang bertujuan untuk mengkoreksi apakah desain yang dibuat sudah sesuai sebelum pengembangan sebuah produk [12]. Metode ini digunakan karena memiliki keunggulan yaitu meminimalkan overhead perencanaan, mudah di mengerti dan diimplementasikan serta tahap diproses dan diselesaikan satu persatu [12]. Diagram waterfall ditunjukkan pada Gambar 1 [13].

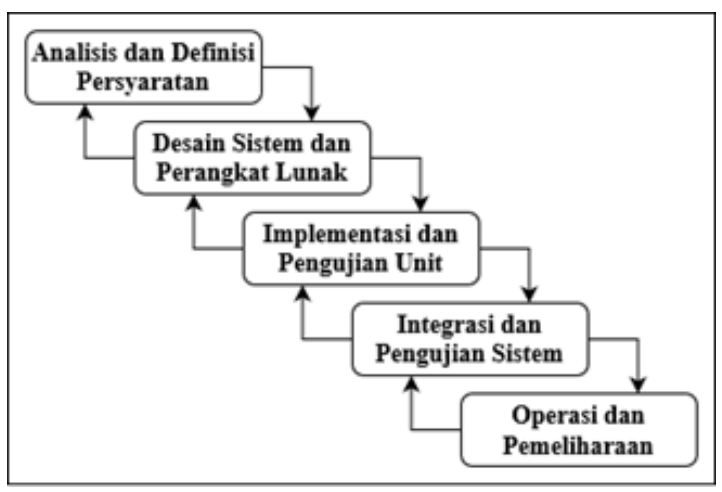

Gambar 1. Struktur metode waterfall

\section{A. Analisis kebutuhan}

Sistem Informasi Geografis yang diperlukan yaitu sistem informasi geografis yang dapat memperlihatkan persebaran dari lokasi serta informasi sekolah di kota Surakarta. Oleh karena itu diperlukan data mengenai koordinat lokasi serta informasi umum mengenai sekolah yang di dapat melalui observasi langsung atau menggunakan internet (web kemdikbud). Setelah mendapatkan data selanjutnya melakukan identifikasi kebutuhan perangkat keras, perangkat lunak dan olah pikir. Terdapat tiga analisis kebutuhan yaitu kebutuhan fungsional, kebutuhan hardware, dan kebutuhan software. Untuk analisis kebutuhan fungsional terdapat dua kategori:

1) Kebutuhan fungsional admin. Admin disini bertugas untuk mengelola data pendidikan. Sebelum menambahkan, mengubah atau menghapus data sekolah admin perlu melakukan login sebelumnya, serta admin juga bisa memberikan penambahan layer batas-batas wilayah

2) Kebutuhan fungsional user. User atau pengunjung website dapat melihat peta pesebaran sekolah, mencari sekolah 
yang diinginkan, menampilkan layer batas wilayah kecamatan/kelurahan serta dapat menggunakan GPS untuk menentukan lokasi dimana user berada.

Sedangkan untuk analisis Kebutuhan Hardware maka memerlukan perangkat sebagai berikut: laptop (Processor core i5, RAM 8GB DDR4, HDD 1TB, SSD 250GB, VGA Nvidia GeForce 930Mx 2GB) sebagai alat untuk membuat sistem, mouse dan printer. Terakhir, analisis Kebutuhan Software maka menggunakan rancang bangun sebuah sistem WebGIS dengan menggunakan bahasa pemrogramman PHP pada framework Codeigniter sebagai backend sistem, MySql sebagai Database Manajemen Sistem (DBMS). MySql memiliki beberapa kelebihan seperti tidak berbayar, kecepatan proses yang baik dan mudah digunakan [14]. Selanjutnya DBDesigner dibutuhkan untuk merancang database, serta Visual Studio Code untuk teks editor dalam penulisan kode program. Untuk mengelola bagian frontend penulis menggunakan HTML, CSS serta JavaScript agar tampilan lebih interaktif dan menggunakan library Leaflet untuk pembuatan peta. Dalam menjalankan sebuah website diperlukan adanya web server seperti apache yang melayani permintaan pengguna dan menghubungkan dengan server basis data [15].

\section{B. Desain Sistem}

Setelah analisis kebutuhan diperlukan adanya desain sistem untuk merancang dan mengembangkan latar belakang pada sistem yang nantinya dibuat dan untuk pengembangan user interface penulis menggunakan framework bootstrap [16].

1) 1) Use Case Diagram. Pada dasarnya use case diagram diperlukan untuk memberikan gambaran kepada pengembang mengenai tindakan yang dilakukan sistem untuk menghasilkan nilai atau hasil yang dapat diamati oleh aktor [17]. Pada sistem yang penulis buat hanya terdapat dua aktor yaitu pengguna sebagai pengunjung web yang memerlukan informasi pesebaran sekolah di kota Surakarta serta admin sebagai orang yang mengolah data dan memperbaharui data sekolah. Use case diagram untuk sistem ini ditunjukkan pada Gambar 2.

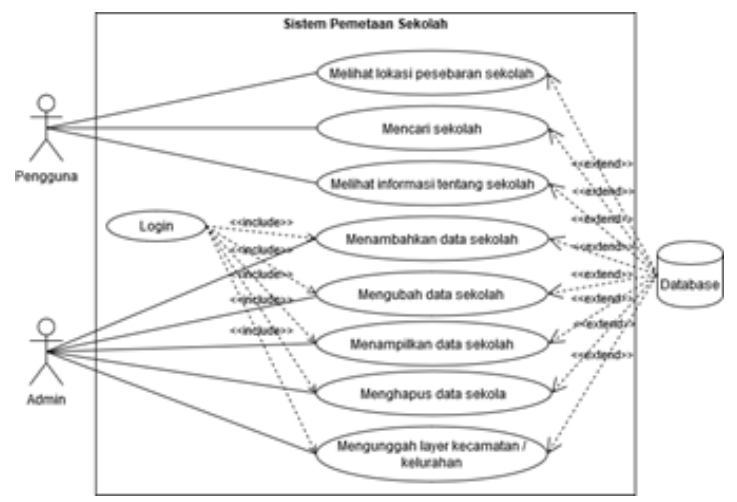

Gambar 2. Use case diagram

2) Diagram aktivitas. Diagram aktivitas berfungsi dalam menggambarkan proses berurutan pada aktivitas use case dari awal hingga akhir aktivitas dan juga sebagai pemodelan logika dengan sistem agar lebih mudah dipahami [18]. Diagram aktivitas proses login yang dimana seorang admin perlu melakukan proses login untuk memiliki akses kedalam sistem. Ditunjukkan pada Gambar 3.

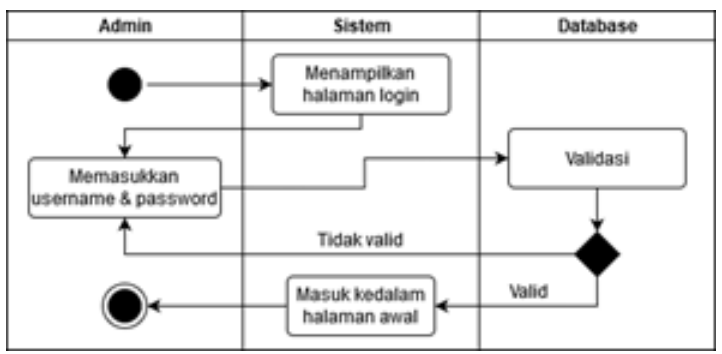

Gambar 3. Diagram aktivitas proses login

Diagram aktivitas proses manipulasi data sekolah, dilakukan ketika admin ingin menambahkan, mengubah atau menghapus data sekolah. Ditunjukkan pada Gambar 4.

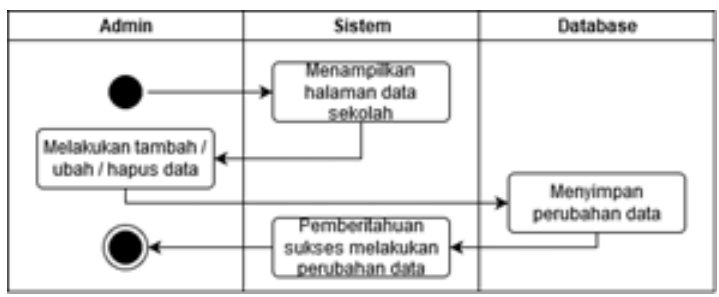

Gambar 4. Diagram aktivitas proses manipulasi data sekolah

c) Diagram aktivitas proses unggah file layer. Admin akan mengunggah file berformat geojson untuk disimpan pada sistem dan menampilkan batasan wilayah. Ditunjukkan pada Gambar 5.

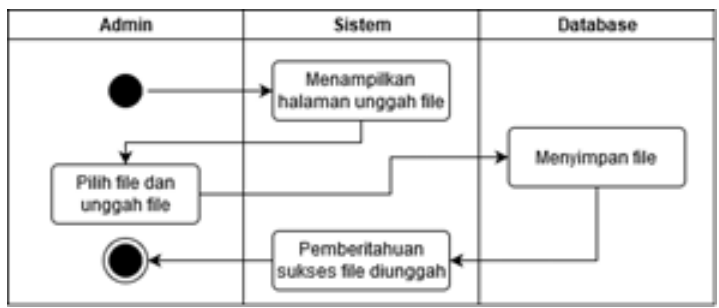

Gambar 5. Diagram aktivitas proses unggah file layer

d) Diagram aktivitas proses pencarian oleh pengguna. Berikut adalah bagaimana alur pengguna dalam menggunakan sistem. Ditunjukkan pada Gambar 6.

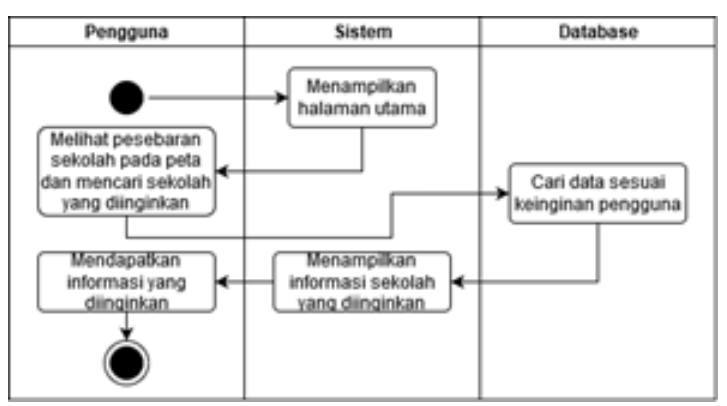

Gambar 6. Diagram aktivitas proses pencarian sekolah oleh pengguna

3) Perancangan Basis Data (database). Perancangan basis data adalah suatu proses untuk menghasilkan model data 
yang terperinci serta terstruktur dari basis data [19]. Pada saat perancangan desain basis data, penulis menggunakan DB Designer 4 yang digunakan untuk menentukan entitas, atribut serta relasi yang diperlukan untuk membuat sistem yang penulis buat. Rancangan basis data fisik dapat dilihat pada Gambar 7.

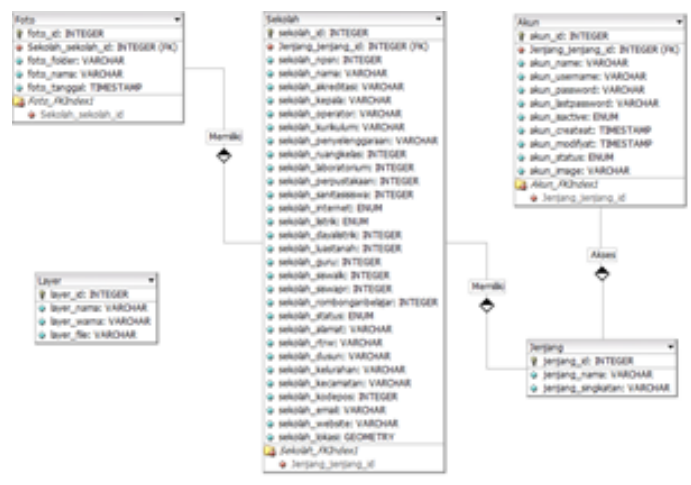

Gambar 7. Basis data fisik

\section{Pengkodean}

Berdasarkan hasil rancangan yang sudah dibuat perlu diubah kedalam bentuk kode program agar menjadi sistem yang utuh. Pada tahap ini akan menghasilkan kode program yang sesuai pada rancangan yang sudah dibuat [20]. Dalam penelitian ini penulis memakai bahasa pemrogramman PHP dengan framework Codeigniter. Dengan menggunakan Codeigniter dapat memudahkan dalam pengembangan sistem karena akan lebih terstruktur dan terorganisir, serta mengikuti perkembangan teknologi informasi [21]. Karena sistem yang dibangun merupakan WebGIS maka penulis menggunakan Leaflet Javascript Library sebagai pengolah data spasial kedalam bentuk peta.

\section{Pengujian}

Pada tahapan pengujian ini metode Black-box dan System Usability Score (SUS) digunakan untuk mendapatkan kesalahan atau kekurangan yang mungkin terjadi pada software yang akan diuji [22]. Black-box adalah pengujian yang fokus pada hasil sebagai respon input daripada berfokus pada mekanisme internal [23]. Sedangkan SUS adalah alat yang digunakan untuk menilai sebuah produk dengan memberikan nilai terhadap kegunaan produk atau layanan tersebut [24]. Dalam pengujian Black-box penulis menguji beberapa fungsional seperti dapat menambahkan, mengubah dan menghapus data dengan baik serta menampilkan peta pesebaran SMA / SMK dan fitur yang tersedia ditampilkan dengan tidak ada error. Dalam melakukan SUS sebaran kuisioner akan diberikan kepada pengunjung website yang penulis buat, karena siapa saja dapat membutuhkan informasi mengenai pesebaran sekolah di kota Surakarta.

\section{E. Pemeliharaan}

Pada tahap ini, sebuah sistem yang sudah jadi dapat mengalami kendala error setelah dikirim ke pengguna. Error atau kesalahan dapat terjadi karena adanya faktor yang mungkin tidak ditemukan saat pengujian sistem [25]. Untuk itu perlu dilakukan pemantauan serta perawatan agar tidak terjadi kegagalan sistem. Pemantauan dan perawatan akan dilakukan oleh pengembang apabila terjadi kerusakan atau kegagalan sistem.

\section{HASIL DAN PEMBAHASAN}

Hasil daripada penelitian ini setelah pembuatan sistem yaitu menghasilkan suatu Sistem Informasi Geografis Pemetaan Sekolah Menengah Atas / Sederajat Di Kota Surakarta Menggunakan Leaflet Javascript Library Berbasis Website. Sistem ini membantu masyarakat dalam menemukan lokasi serta informasi profil sekolah yang ada di Surakarta. Sistem ini memiliki dua tampilan yang berbeda untuk admin dan user (masyarakat). Berikut adalah hasil dari penelitian.

Halaman home (bagian depan atau beranda) yaitu halaman yang akan muncul pertama kali pada saat mengakses sistem. Pada bagian halaman ini memiliki dua menu yaitu home dan about yang dimana home akan mengarahkan paa halaman ini sendiri sedangkan about akan mengarahkan pada file pdf yang berisi tentang penjelasan singkat sistem ini. Halaman ini merupakan fungsi utama dari sistem karena pada halaman ini user dapat mencari lokasi sekolah berdasarkan peta sebaran sekolah yang tersedia serta terdapat beberapa fitur yang dapat digunakan seperti mengukur jarak, menggunakan GPS, memberikan lingkaran radius dari posisi pengguna serta dapat melakukan filter sekolah berdasarkan jenjang, status dan nama sekolah. Halaman home ditunjukkan pada Gambar 8.
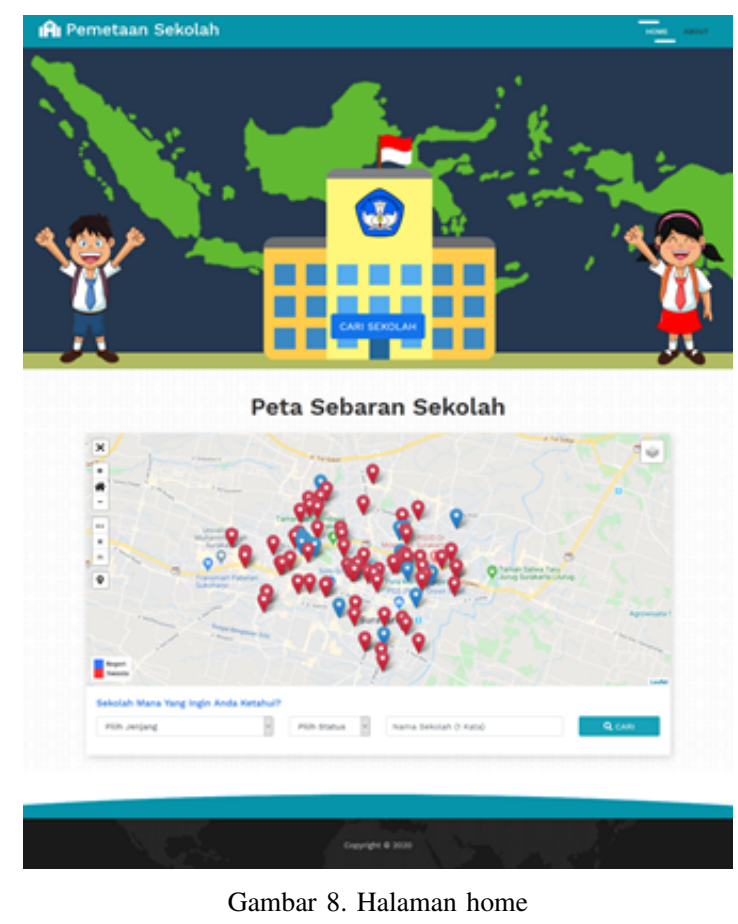

Halaman profil yaitu halaman yang akan muncul saat pengguna menekan salah satu pin pada peta yang nantinya akan muncul popup nama sekolah dan ketika nama itu ditekan maka akan menuju ke halaman profil dari sekolah tersebut. Pada halaman profil ini memuat tentang gambaran umum sekolah yaitu jumlah siswa, guru, sarana prasarana, akreditasi, alamat, kepala sekolah, lokasi dan foto sekolah. Halaman profil ditunjukkan pada Gambar 9. 

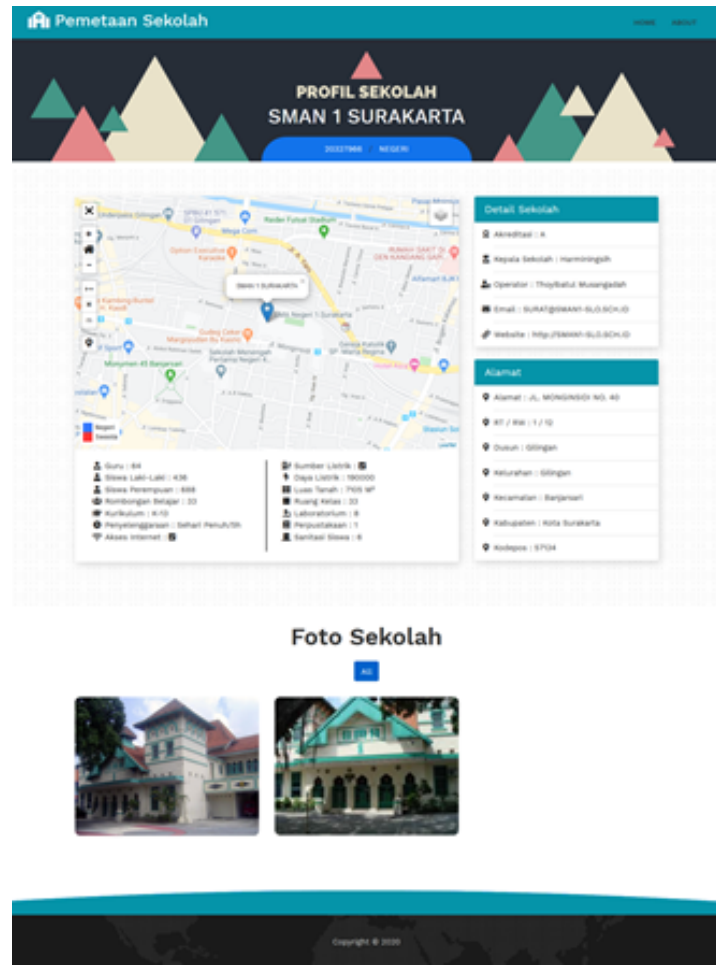

Gambar 9. Halaman profil

Halaman login yaitu halaman yang akan ditampilkan sebelum masuk kedalam sistem admin. Sebelumnya admin akan diminta untuk memasukkan username dan password akun admin, hal itu untuk mengamankan sistem agar hanya orang tertentu (admin) yang bisa masuk. Halaman login ditunjukkan pada Gambar 10.

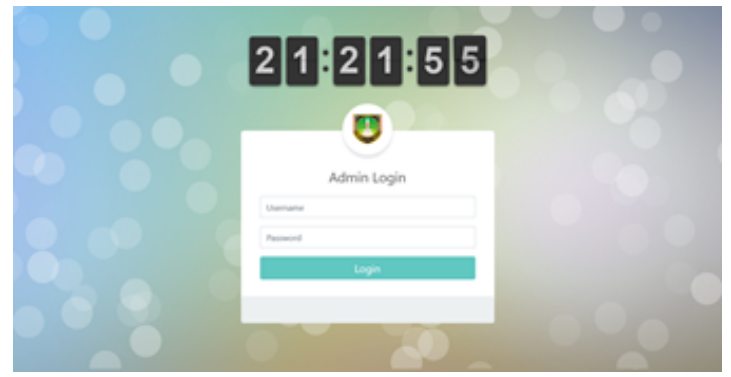

Gambar 10. Halaman login

Halaman dashboard yaitu halaman yang muncul pada saat admin berhasil melakukan login kedalam sistem admin. Halaman ini memiliki informasi mengenai total data sekolah, negeri dan swasta. Pada halaman admin ini terdapat sidebar di sisi kiri yang berisi menu dashboard, account, grade, school, layer serta maps. Untuk melakukan logout pada sistem admin ini terdapat tombol pada pojok kanan atas halaman setelah menekan nama admin maka akan muncul tombol logout. Halaman dashboard ditunjukkan pada Gambar 11.

Halaman tabel pada masing-masing submenu (Account, Grade, School, Layer). Pada halaman ini memiliki informasi tentang data yang tersimpan dalam database. Pada halaman tabel ini admin mampu melakukan penambahan data, mengganti data dan juga menghapus data yang sudah di tambahkan. Pada tabel sekolah terdapat tombol untuk menujuku ke tabel gallery

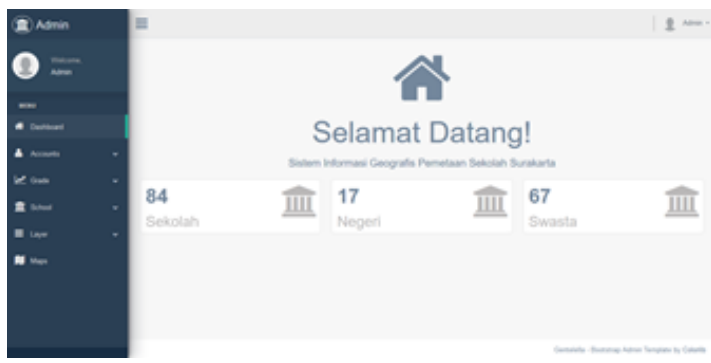

Gambar 11. Halaman dashboard

sekolah yang berisi data foto sekolah. Sedangkan pada tabel layer terdapat tombol untuk mendownload layer yang sudah disimpan ke server. Halaman tabel ditunjukkan pada Gambar 12.

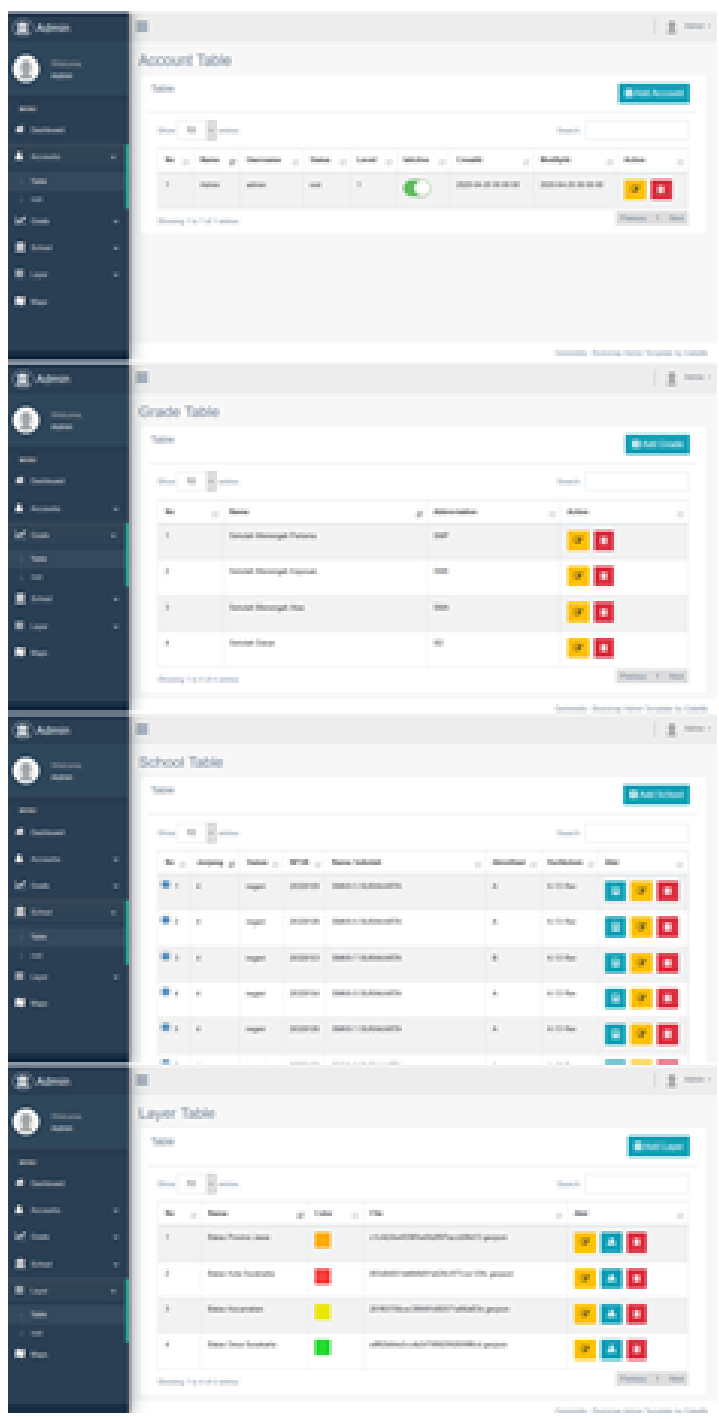

Gambar 12. Halaman tabel (Account, Grade, School, Layer)

Halaman maps merupakan halaman yang berisikan peta sebaran sekolah di surakarta. Halaman ini mirip dengan halaman home yang terdapat diawal, yang berfungsi untuk membantu admin dalam memonitoring data apakah data lokasi sekolah sudah masuk kedalam peta. Halaman maps ditunjukkan pada Gambar 13. 
Tabel I. Hasil pengujian black-box

\begin{tabular}{|c|c|c|c|c|}
\hline No. & Kelas Uji & Skenario & Harapan & Hasil \\
\hline \multirow[t]{7}{*}{1} & Pencarian Sekolah & Mengisi jenjang, status dan nama sekolah benar & Tanda lokasi sekolah muncul sesuai dengan yang dicari & Valid \\
\hline & & Mengisi jenjang, status dan nama sekolah salah & Sistem memunculkan popup bahwa data tidak ada & Valid \\
\hline & & Menekan tombol ukur jarak pada eta & Pengguna dapat melakukan pengukuran jarak pada peta & Valid \\
\hline & & Menekan tombol GPS pada peta & Pengguna mengetahui lokasi keberadaannya pada peta & Valid \\
\hline & & Menekan tombol radius pada sistem & Sistem menampilkan lingkaran radius dari lokasi pengguna & Valid \\
\hline & & Menambahkan layer batas wilayah pada peta & Sistem menampilkan layer batas wilayah & Valid \\
\hline & & $\begin{array}{l}\text { Menekan pin (marker) sekolah untuk melihat profil } \\
\text { sekolah }\end{array}$ & $\begin{array}{l}\text { Sistem menuju ke halaman baru untuk menampilkan profil } \\
\text { sekolah yang ditekan oleh user }\end{array}$ & Valid \\
\hline 2 & Profil Sekolah & Menekan foto sekolah & Foto tampil dan dapat di geser & Valid \\
\hline \multirow[t]{2}{*}{3} & Login & $\begin{array}{l}\text { Mengisi kolom input username dan password dengan } \\
\text { benar }\end{array}$ & $\begin{array}{l}\text { Sistem berhasil masuk atau login pada halaman dashboard } \\
\text { admin }\end{array}$ & Valid \\
\hline & & $\begin{array}{l}\text { Mengisi kolom input username dan password dengan } \\
\text { salah }\end{array}$ & $\begin{array}{l}\text { Sistem berhasil kembali pada halaman login dan menampilk- } \\
\text { an kesalahan }\end{array}$ & Valid \\
\hline 4 & Logout & Menekan tombol logout pada sistem & $\begin{array}{l}\text { Data login terhapus dari sistem dan kembali pada halaman } \\
\text { login }\end{array}$ & Valid \\
\hline \multirow[t]{2}{*}{5} & Menu Account & Menekan menu account dan memilih submenu table & $\begin{array}{l}\text { Masuk pada halaman account table dan menampilkan semua } \\
\text { data akun }\end{array}$ & Valid \\
\hline & & $\begin{array}{l}\text { Admin menambah, mengganti serta menghapus data } \\
\text { akun }\end{array}$ & $\begin{array}{l}\text { Data pada tabel akun dapat ditambah, diganti serta dihapus } \\
\text { secara permanen }\end{array}$ & Valid \\
\hline \multirow[t]{2}{*}{6} & Menu Grade & Menekan menu grade dan memilih submenu table & $\begin{array}{l}\text { Masuk pada halaman grade table dan menampilkan semua } \\
\text { data jenjang }\end{array}$ & Valid \\
\hline & & $\begin{array}{l}\text { Admin menambah, mengganti serta menghapus data } \\
\text { jenjang }\end{array}$ & $\begin{array}{l}\text { Data pada tabel jenjang dapat ditambah, diganti serta dihapus } \\
\text { secara permanen }\end{array}$ & Valid \\
\hline \multirow[t]{4}{*}{7} & Menu School & Menekan menu school dan memilih submenu table & $\begin{array}{l}\text { Masuk pada halaman school table dan menampilkan semua } \\
\text { data sekolah }\end{array}$ & Valid \\
\hline & & $\begin{array}{l}\text { Admin menambah, mengganti serta menghapus data } \\
\text { sekolah }\end{array}$ & $\begin{array}{l}\text { Data pada tabel sekolah dapat ditambah, diganti serta dihapus } \\
\text { secara permanen }\end{array}$ & Valid \\
\hline & & Menekan tombol gallery pada salah satu data sekolah & Masuk pada halaman gallery dari sekolah yang dipilih & Valid \\
\hline & & $\begin{array}{l}\text { Admin menambah, mengganti serta menghapus data } \\
\text { gallery }\end{array}$ & $\begin{array}{l}\text { Data pada tabel gallery dapat ditambah, diganti serta dihapus } \\
\text { secara permanen }\end{array}$ & Valid \\
\hline \multirow[t]{3}{*}{8} & Menu Layer & Menekan menu layer dan memilih submenu table & $\begin{array}{l}\text { Masuk pada halaman layer table dan menampilkan semua data } \\
\text { layer }\end{array}$ & Valid \\
\hline & & $\begin{array}{l}\text { Admin menambah, mengganti serta menghapus data } \\
\text { layer }\end{array}$ & $\begin{array}{l}\text { Data pada tabel layer dapat ditambah, diganti serta dihapus } \\
\text { secara permanen }\end{array}$ & Valid \\
\hline & & Menekan tombol download pada salah satu data layer & File layer ter-download & Valid \\
\hline 9 & Menu Maps & Memonitoring data lokasi sekolah & Menampilkan data lokasi sekolah & Valid \\
\hline
\end{tabular}

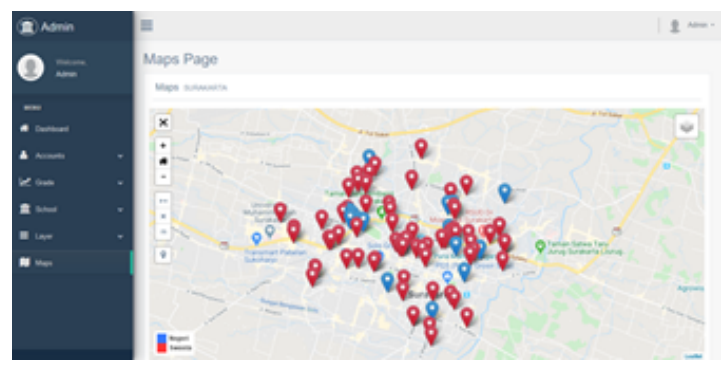

Gambar 13. Halaman maps

Pengetesan Black-Box diperlukan guna memastikan apakah proses sistem yang berjalan sudah sinkron dengan hasil yang diharapakan menurut fungsional sistemya. Hasil pengujian Black-Box ditunjukkan pada Tabel I.

Pengujian sistem denga memakai metode System Usability Scale (SUS) dilakukan sesudah pengujian Black-Box dan dilakukan setelah pengguna menggunakan secara langsung sistem, untuk mengetahui evaluasi dari sitem yang digunakan. Terdapat 10 macam pertanyaan pada metode SUS dan memiliki 5 opsi jawaban yaitu Sangat Tidak Setuju (STS), sampai dengan Sangat Setuju (SS). Metode SUS memiliki skala 1-5 dan skor 04 pada setiap pertanyaannya. Perhitungan skor dibedakan untuk pertanyaan ganjil dan genap. Untuk pertanyaan dengan nomor ganjil perhitungannya adalah (skala 1). Sedangkan untuk pertanyaan yang memiliki nomor urut genap perhitungannya adalah
(5 skala). Tahap berikutnya yaitu tiap skor nomor ganjil dan genap ditambahkan dan kemudian dikalikan dengan 2,5 untuk mendapatkan hasil skor tiap responden. Skor SUS didapatkan dari penjumlahan seluruh skor responden dibagi dengan jumlah responden [26]. Skor SUS mempunyai 3 klasifikasi diantaranya adalah not acceptable, marginal dan acceptable dengan rentang nilai yang ditunjukkan pada Gambar 14 [27].

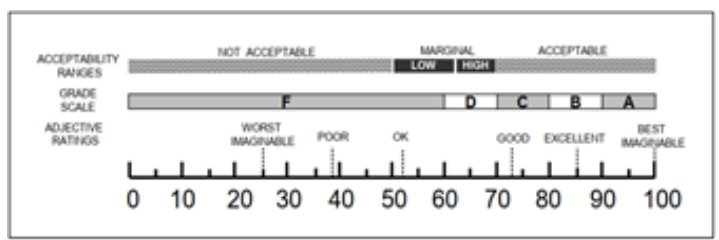

Gambar 14. Rentang nilai System Usability Scale

Daftar pernyataan untuk responden ditunjukkan pada Tabel II. Kemudian, dari daftar pernyataan pada Tabel II, didapatkan perhitungan total dari responden. Hasil perhitungan ditunjukkan pada Tabel III.

\section{KESIMPULAN}

Sistem informasi geografis untuk pemetaan sekolah menengah atas / sederajat pada Kota Surakarta menggunakan leaflet javascript library berbasis website telah selesai dibuat dan berjalan sesuai yang diharapkan. Sistem dibuat menggunakan library leaflet dapat mempermudah peneliti dalam pembuatan 
Tabel II. Pernyataan system utility scale

\begin{tabular}{|c|c|}
\hline No. & Pernyataan \\
\hline 1 & Saya kira sistem ini akan sering saya gunakan lagi \\
\hline 2 & $\begin{array}{l}\text { Saya rasa sistem ini sangat kompleks hingga membuat saya } \\
\text { kesulitan }\end{array}$ \\
\hline 3 & Saya menilai mudah menggunakan sistem ini \\
\hline 4 & $\begin{array}{l}\text { Saya harus dibantu oleh orang lain untuk bisa menggunakan } \\
\text { sistem ini }\end{array}$ \\
\hline 5 & $\begin{array}{l}\text { Saya menilai sistem ini memiliki fitur yang dapat berjalan } \\
\text { dengan baik }\end{array}$ \\
\hline 6 & Saya pikir sistem ini terdapat banyak hal yang tidak konsisten \\
\hline 7 & $\begin{array}{l}\text { Saya rasa sistem ini dapat dipelajari dengan mudah oleh } \\
\text { pengguna }\end{array}$ \\
\hline 8 & Saya pikir sistem ini tidak efisien dan bikin bingung \\
\hline 9 & Saya merasa sangat percaya diri menggunakan sistem ini \\
\hline 10 & $\begin{array}{l}\text { Saya perlu belajar banyak hal pada sistem ini terlebih dahulu, } \\
\text { sebelum dapat memakai sistem ini }\end{array}$ \\
\hline
\end{tabular}

Tabel III. Hasil pengujian system usability scale

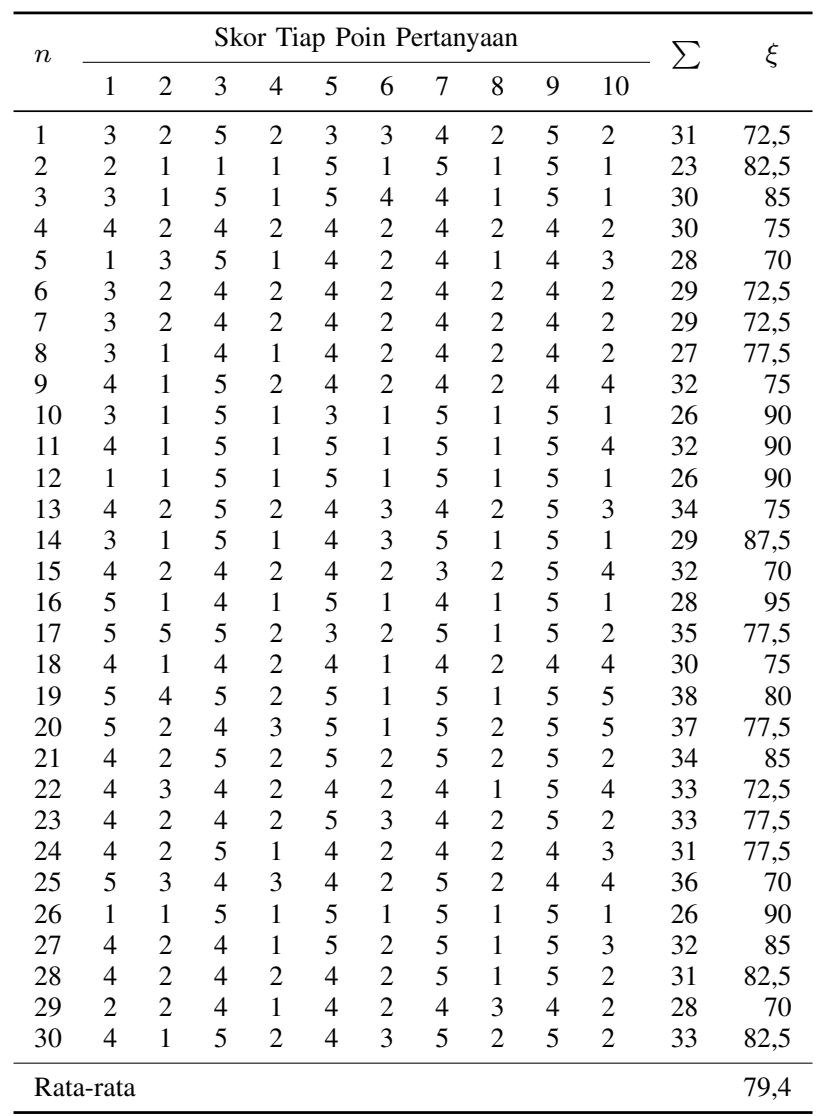

Keterangan: $n$ adalah responden; $\sum$ adalah jumlah, dan $\xi$ adalah jumlah akhir

peta serta beberapa fitur dapat dibuat dengan menggunakan plugin yang sudah tersedia di internet dan bersifat open source. Hal ini lebih unggul daripada menggunakan Google Maps API karena dapat dikembangkan secara fleksibel. Sistem ini dapat dijalankan sesuai dengan tujuannya yaitu mempermudah pengguna (masyarakat) untuk memperoleh lokasi serta informasi profil sekolah yang berada di Kota Surakarta. Pada pengetesan Black-box memiliki hasil yang secara fungsional sistem dapat berjalan sesuai yang diharapkan. Kemudian pada pengujian Usability diperoleh skor SUS yaitu 79,4, yang menunjukan bahwa sistem dapat diterima oleh masyarakat dan menunjukan klasifikasi sistem yang baik. Pada pengembangan sistem ini, selanjutnya diharapkan dapat menambahkan fitur untuk membandingkan beberapa sekolah yang dipilih sehingga lebih mempermudah masyarakat dalam menentukan sekolah yang sesuai keinginan.

\section{DAFTAR PUSTAKA}

[1] M. P. Dewi, "plikasi pemetaan gps smp sma surakarta berbasis mobile android," Skripsi - Universitas Muhammadiyah Surakarta, 2016.

[2] I. Arifuddin, N. W. Sari, S. H. Susanto, dan I. C. Sayekti, "Sistem zonasi, antara realita dan harapan," no. 1, 2019.

[3] Prayoga, P. Bagas, S. DK, dan Jasmani, "Pemanfaatan sistem informasi geografis berbasis web untuk menentukan zonasi sekolah menengah pertama (smp) dalam penerimaan peserta didik baru (ppdb) (studi kasus: Kota malang)," Eprints ITN Malang, pp. 1-8, 2019.

[4] N. Rizky, Y. Rachman, A. L. Nugraha, dan A. P. Wijaya, "Aplikasi sistem informasi geografis berbasis web untuk persebaran sekolah menengah atas (studi kasus: Kota semarang)," Jurnal Geodesi Undip, vol. 4, no. 1, 2015.

[5] R. Amelia, "Sistem informasi geografis lokasi sma di kota padang berbasis web," Jurnal Teknologi Informasi dan Pendidikan, vol. 9, no. 3, pp. 140-146, 2016.

[6] "Sistem informasi geografis pemetaan sekolah berbasis mobile (studi kasus smp negeri di kecamatan tampan pekanbaru)," Universitas PGRI Semarang, vol. Vol 3, No 2: Desember (2017), 2017.

[7] M. A. Husaini dan W. Dwi P, "Sistem informasi geografis (sig) pemetaan sekolah berbasis web di kecamatan wonodadi kabupaten blitar," Antivirus : Jurnal Ilmiah Teknik Informatika, vol. 11, no. 1, May 2017.

[8] E. J. Tanjaya, S. Rostianingsih, dan A. Handojo, "Pemetaan surabaya heritage dengan geographic information system," JURNAL INFRA, vol. 4 , no. $2,2016$.

[9] M. Wardana dan M. Jazman, "Rancang bangun sistem informasi geogafis pemetaan ruang ujian menggunakan bootstrap dan leaflet.js (studi kasus: Fakultas sains dan teknologi uin suska riau)," " 052017.

[10] A. Annugerah, I. Astuti, dan A. harsa kridalaksana, "Sistem informasi geografis berbasis web pemetaan lokasi toko oleh-oleh khas samarinda," Informatika Mulawarman : Jurnal Ilmiah Ilmu Komputer, vol. 11, p. 43, 2016.

[11] D. Refaat dan N. Ramadan, "Extracting crm requirements - waterfall or agile: A comparative study," vol. 4, pp. 1-5, 2019.

[12] A. Alshamrani, A. A. Bahattab, dan I. A. Fulton, "A comparison between three sdlc models waterfall model, spiral model, and incremental/iterative model," " 2015.

[13] S. S. Putra, G. Susilo, dan C. Sundari, "Sistem informasi geografis pemetaan lahan pertanian tembakau di kecamatan kledung, kabupaten temanggung," Jurnal Transformasi, vol. 5, no. 2, 2019.

[14] D. Anggoro dan W. Supriyanti, "Aplikasi sistem pendukung keputusan dengan metode ahp untuk pemilihan siswa berprestasi di sman kebakkramat," Jurnal Penelitian dan Pengabdian Kepada Masyarakat UNSIQ, vol. 6, pp. 163-171, 092019.

[15] H. Supriyono, A. Sutopo, H. Nursyahid, B. A. Kurniawan, I. N. Fahrudin, D. Handoko, I. Rivai, dan D. C. Kurniawan, "Penerapan teknologi web sekolah bagi smp dan sma muhammadiyah kartasura," Warta LPM, vol. 19, no. $1,2016$.

[16] K. Zhao, R. Sun, C. Deng, L. Li, Q. Wu, dan S. Li, "Visual analysis system for market sales data of agricultural products," IFACPapersOnLine, vol. 51, no. 17, pp. 741 - 746, 2018, 6th IFAC Conference on Bio-Robotics BIOROBOTICS 2018.

[17] M. Bhuiyan, F. Haque, dan L. Shabnam, "Integration of organisational models and uml use case," Journal of Computers, vol. 13, pp. 1-17, 01 2018.

[18] Meiliana, I. Septian, R. S. Alianto, Daniel, dan F. L. Gaol, "Automated test case generation from uml activity diagram and sequence diagram using depth first search algorithm," Procedia Computer Science, vol. 116 , pp. $629-637,2017$, discovery and innovation of computer science technology in artificial intelligence era: The 2nd International Conference on Computer Science and Computational Intelligence (ICCSCI 2017).

[19] P. D. Silva, "Sales and inventory management system for imperial auto care," Jap Telecommun Rev, 2017.

[20] M. Tabrani, "Penerapan metode waterfall pada sistem informasi inventori pt. pangan sehat sejahtera," Jurnal Inkofar, vol. 1, no. 2, 2017.

[21] M. T. Muslihi, "Development and functional testing on codeigniter framework based academic system," Indonesian Journal of Information Technology, vol. 1, no. 2, 2017.

[22] U. Salamah dan F. N. Khasanah, "Pengujian sistem informasi penjualan undangan pernikahan online berbasis web menggunakan black box testing," INFORMATION MANAGEMENT FOR EDUCATORS AND PROFESSIONALS, vol. 2, no. 1, 2017. 
[23] H. Bhasin, E. Khanna, dan Sudha, "Black box testing based on requirement analysis and design specifications," International Journal of Computer Applications, vol. 87, pp. 36-40, 2014.

[24] A. I. Martins, A. F. Rosa, A. Queirs, A. Silva, dan N. P. Rocha, "European portuguese validation of the system usability scale (sus)," Procedia Computer Science, vol. 67, pp. 293 - 300, 2015, proceedings of the 6th International Conference on Software Development and
Technologies for Enhancing Accessibility and Fighting Info-exclusion.

[25] R. A. Sagita dan H. Sugiarto, "Penerapan metode waterfall pada sistem informasi furniture berbasis web," IJNS, vol. 5, no. 4, 2016.

[26] J. Brooke, "Sus - a quick and dirty usability scale," " 2006.

[27] A. Bangor, P. Kortum, dan J. Miller, "Determining what individual sus scores mean: Adding an adjective rating scale," J. Usability Stud., vol. 4, pp. 114-123, 042009 . 